\title{
Altered $\mathrm{T}$ cell responses in children with autism
}

\author{
Paul Ashwood ${ }^{1,6,{ }^{*}}$, Paula Krakowiak ${ }^{2}$, Irva Hertz-Picciotto ${ }^{2,6}$, Robin Hansen ${ }^{3,6}$, Isaac N. \\ Pessah $^{4,6}$, and Judy Van de Water ${ }^{5,6}$ \\ 1 Department of Medical Microbiology and Immunology, University of California, Davis, CA \\ 2 Department of Public Health Sciences, Division of Epidemiology, University of California, Davis, \\ $\mathrm{CA}$ \\ ${ }^{3}$ Department of Pediatrics, School of Medicine, University of California, Davis, CA \\ 4 Department of Molecular Biosciences, School of Veterinary Medicine, University of California, \\ Davis, CA \\ ${ }^{5}$ Division of Rheumatology, Allergy and Clinical Immunology, University of California, Davis, CA \\ 6 The Medical Investigation of Neuodevelopmental Disorders (M.I.N.D.) Institute, UC Davis Health \\ System, Sacramento, CA
}

\section{Abstract}

\begin{abstract}
Autism spectrum disorders (ASD) are characterized by impairment in social interactions, communication deficits, and restricted repetitive interests and behaviors. A potential etiologic role for immune dysfunction in ASD has been suggested. Dynamic adaptive cellular immune function was investigated in 66 children with a confirmed diagnosis of ASD and 73 confirmed typically developing (TD) controls 2-5 years-of-age. In vitro stimulation of peripheral blood mononuclear cells with PHA and tetanus was used to compare group-associated cellular responses. The production of GM-CSF, TNF $\alpha$, and IL-13 were significantly increased whereas IL-12p40 was decreased following PHA stimulation in ASD relative to TD controls. Induced cytokine production was associated with altered behaviors in ASD children such that increased proinflammatory or $\mathrm{T}_{\mathrm{H}} 1$ cytokines were associated with greater impairments in core features of ASD as well as aberrant behaviors. In contrast, production of GM-CSF and $\mathrm{T}_{\mathrm{H}} 2$ cytokines were associated with better cognitive and adaptive function. Following stimulation, the frequency of $\mathrm{CD}^{+}, \mathrm{CD}^{+}$and $\mathrm{CD} 8^{+} \mathrm{T}$ cells expressing activation markers $\mathrm{CD} 134$ and $\mathrm{CD} 25$ but not CD69, HLA-DR or CD137 were significantly reduced in ASD, and suggests an altered activation profile for $\mathrm{T}$ cells in ASD. Overall these data indicate significantly altered adaptive cellular immune function in children with ASD that may reflect dysfunctional immune activation, along with evidence that these perturbations may be linked to disturbances in behavior and developmental functioning. Further longitudinal analyzes of cellular immunity profiles would delineate the relationship between immune dysfunction and the progression of behavioral and developmental changes throughout the course of this disorder.
\end{abstract}

\footnotetext{
*Address for Correspondence: Dr Paul Ashwood, Department of Microbiology and Immunology, and the M.I.N.D. Institute, 2805, $50^{\text {th }}$ Street, Sacramento, CA 95817, pashwood@ucdavis.edu.

Publisher's Disclaimer: This is a PDF file of an unedited manuscript that has been accepted for publication. As a service to our customers we are providing this early version of the manuscript. The manuscript will undergo copyediting, typesetting, and review of the resulting proof before it is published in its final citable form. Please note that during the production process errors may be discovered which could affect the content, and all legal disclaimers that apply to the journal pertain.
} 


\section{Introduction}

Autism spectrum disorders (ASD) are a heterogeneous group of neurodevelopmental disorders that include autistic disorder, Asperger's disorder and pervasive developmental disorder, not otherwise specified (APA, 2000). Children with ASD have significant deficits in communication and social interactions and exhibit stereotyped or restricted behaviors and interests. Recent epidemiologic data suggest that approximately 1 in 100 children are diagnosed with an ASD \{MMWR, 2009\}. The etiology of autism is complex and largely unknown, although it is highly heritable. While many studies yield evidence that there are genes that strongly impact the likelihood of developing autism, no definitive pattern of genes has been identified despite a multitude of different and varied candidate genes that have been implicated in ASD (Muhle et al., 2004). Moreover, replication of these data has been inconsistent; probably due in part to the heterogeneity of the phenotypes within the autism spectrum. However, among the potential genetic candidates several studies have linked ASD with immune-based genes, such as human leukocyte antigen (HLA)-DRB $1 * 04$, interleukin (IL)-4 receptor, and complement C4B null allele (Lee et al., 2006; Torres et al., 2006; Warren et al. 1992; Warren et al., 1995), as well as a number of other immune-related genes including macrophage migration inhibitory factor (MIF) (Grigorenko et al., 2008), MET tyrosine receptors (Campbell et al., 2006; Campbell et al., 2007; Garbett et al., 2008), serine and threonine kinase $\mathrm{C}$ gene PRKCBI (Lintas et al., 2009), protein phosphatase and tensin homolog (PTEN) (Herman et al., 2007), and reelin (Serajee et al., 2006; Skaar et al., 2005). In addition, epidemiology studies have demonstrated associations between increased early-life infections and later ASD diagnosis (Niehus and Lord 2006; Rosen, Yoshida, and Croen 2007; Atladottir, 2010) supporting a potential role for abnormal immune dysfunction in ASD. Moreover, associations with maternal autoimmunity (Comi et al., 1999; Croen et al., 2005; Molloy et al., 2006; Atladottir et al., 2009) or maternal diagnosis of allergy/asthma in the second trimester of pregnancy and an ASD diagnosis in the offspring (Croen et al., 2005), suggests that inappropriate maternal immune responses may alter the course of immune and neurodevelopment.

Quantitative and qualitative differences in immune function between children with ASD and typically developing (TD) controls have been demonstrated, including evidence for increased neuroinflammation and cytokine production in brain specimens obtained from subjects with ASD (Vargas et al., 2005; Li et al., 2009; Garbett et al., 2008), as well as elevated levels of pro-inflammatory and decreased levels of regulatory cytokines in the CSF and peripheral blood from children with ASD (Sweeten et al., 2004; Chez et al., 2007; Vargas et al., 2005; Ashwood and Wakefield, 2006; Ashwood et al., 2008). Alterations in both adaptive and innate immune responses have been described in ASD subjects (reviewed in Ashwood et al., 2006; Enstrom et al., 2009a). Abnormal innate immune responses include higher basal NK cell activation (Enstrom et al., 2009b) and increased monocyte responses to toll-like receptor ligation (Enstrom et al., 2010, Jyonouchi et al., 2008). A number of abnormal adaptive responses have been reported in ASD, including increased T lymphocyte cell production of TNF $\alpha$ but decreased IL-10 production (Ashwood et al., 2004; Ashwood and Wakefield 2006, Jyonouchi et al 2001) and, a skewing of cytokine responses towards a $\mathrm{T}_{\mathrm{H}} 2$ cytokine profile (Gupta et al., 1998; Molloy et al., 2005). In addition, there have been reports of altered peripheral T cell activation (Plioplys et al. 1994; Warren et al. 1995), changes in lymphocyte subsets (Yonk et al 1990; Denney et al., 1996), decreased proliferative responses to mitogen stimulation (Stubbs and Crawford, 1977), an imbalance of serum immunoglobulin levels (Enstrom et al., 2009c; Heuer et al., 2008) and the presence of antibodies reactive to brain proteins (Cabanlit et al., 2007; Connolly et al., 2006; Silva et al., 2004; Todd et al., 1988; Wills et al., 2009). Taken together, these findings support noteworthy alterations in the adaptive immune responses in a significant proportion of children with ASD. 
Although several studies have implicated the adaptive immune responses in ASD, many have relied upon small sample sizes, varied diagnostic criteria, disparately aged case and control groups, and unevaluated siblings as controls; these have led to confusion regarding interpretation of the findings. Moreover, the previous studies have not attempted to evaluate the relationship between the adaptive cellular immune response and the core defects of ASD, impairments in associated behaviors, and/or onset patterns of ASD. To better define the adaptive immune status of children with ASD, proliferative and cytokine responses to immune challenge as well as the expression of activation markers on $\mathrm{T}$ cell subsets was evaluated in well-characterized children with ASD and age-matched typically developing control participants in a population-based case-control study. In addition, proliferative and cytokine production in children with ASD was investigated for possible associations with clinical behavioral and developmental function.

\section{Methods}

\section{Subjects}

This study examined 139 participants enrolled through the M.I.N.D. (Medical Investigations of Neurodevelopmental Disorders) Institute clinic and the Center for Children's Environmental Health (CCEH) as part of the ongoing CHARGE (Childhood Autism Risk from Genetics and Environment) study at U.C. Davis (Hertz-Picciotto et al., 2006). The CHARGE study protocols, including details on recruitment and behavioral assessments have been described previously (Ashwood et al., 2008; Hertz-Picciotto et al., 2006; Enstrom et al., 2009b). After clinical evaluations using standardized assessments of behavior and developmental function at the M.I.N.D. clinic by qualified, research-trained clinicians, participants were placed in one of 2 groups: 1) diagnosed with autism spectrum disorders, or 2) confirmed as typically developing controls. This study was approved by the UC Davis institutional review board and complied with all requirements regarding human subjects. Parents gave informed consent. Children were selected based on available blood draws from consecutively recruited participants and were medication free and in good health at time of blood draw. Participants included 66 children with ASD (median age 3.8 years (interquartile range 3.2-4.3), 59 males) and 73 typically developing (TD) controls median age 3.3 years (interquartile range 2.7-4.3), 51 males). Autism spectrum disorder diagnosis was based on criteria set forth in the Diagnostic and Statistical Manual of Mental Disorders, Fourth Edition (DSM-IV) (American Psychiatric Association, 2000) and confirmed and further evaluated using the Autism Diagnostic Interview-Revised (ADI-R) and the Autism Diagnostic Observation Schedule (ADOS) assessments. Children from the TD groups were screened for autism traits using the Social Communication Questionnaire (SCQ). For all children adaptive function was assessed by parental interview using the Vineland Adaptive Behavior Scales (VABS). Additional measures of cognitive ability were determined using the Mullen Scales of Early Learning (MSEL) and abnormal behavior profiles using the Aberrant Behavior Checklist (ABC). Patterns of development were assessed using the Early Development Questionnaire. All the specific behavioral assessments used are disccused in more detail elsewhere (Hertz-Picciotto et al., 2006).

\section{Cell Isolation}

Peripheral blood was drawn from subjects or controls into sodium citrate (ACD) treated vacutainers (BD Bioscience; San Jose, CA). Peripheral blood mononuclear cells (PBMC) were separated from the whole blood by centrifugation over Histopaque-1077 Hybri-Max lymphocyte separation medium (Sigma; St. Louis, MO) before washing twice in Hanks Balanced Salt Solution (HBSS; VWR; Brisbane, CA). The number of viable PBMC was determined by Trypan Blue exclusion (Sigma) and PBMC concentrations were adjusted to $1.5 \times 10^{6}$ cells $/ \mathrm{ml}$ in a solution of $0.1 \% \mathrm{~T}$-Stim (BD Biosciences) in X-Vivo media 
(Cambrex, Walkersville, MD) and were plated in 12-well flat bottom tissue culture plate (Corning, Corning, NY) for stimulation.

\section{Cell stimulation}

PBMC were either cultured in media alone, or stimulated with PHA (10 $\mu \mathrm{g} / \mathrm{mL} ;$ Sigma), or to assess the cellular recall response stimulated with tetanus toxoid ( $1 \mathrm{LF}$ unit/ml, Sigma) for 48 hours at $37^{\circ} \mathrm{C}$ in $5 \% \mathrm{CO}_{2}$. Following culture, plates were centrifuged before supernatants were harvested and stored at $-80^{\circ} \mathrm{C}$ until cytokine analysis. Cells were collected after incubation and used for analysis of cell proliferation (see below). For the experiments involving cell proliferation and cytokine analysis, 37 children with ASD median age 3.6 years (interquartile range 3.1-4.5), 32 males and 35 typically developing (TD) controls median age 3.3 years (interquartile range 2.5-4), 22 males were included.

\section{Cellular proliferation}

Proliferative responses to stimulation were measured using $\left[{ }^{3} \mathrm{H}\right]$ thymidine incorporation into progeny cell DNA. After cells were cultured for 48 hours in the presence of media, PHA or tetanus toxoid to stimulate entry into the cell cycle, cells were pulsed with $0.037 \mathrm{MBq}(1$ $\mu \mathrm{Ci})\left[{ }^{3} \mathrm{H}\right]$ thymidine - with a specific activity of $70-90 \mathrm{Ci}(2.59-3.33 \mathrm{TBq} / \mathrm{mMole},>97 \%$, $5 \mathrm{mCi}(185 \mathrm{MBq})$ - (Sigma) per well for a further 24 hours to allow incorporation into DNA and harvested onto 96 well filter plates (Perkin Elmer) to capture labeled DNA. Proliferation was measured by counting labeled DNA using a scintillation counter (Top Count, Packard) and recorded as counts per minute (cpm). All conditions were carried out in triplicate. Stimulation indexes (S.I.) were determined using the formula: S.I. = stimulated response media response/media response, where stimulated response is either proliferation after stimulation with PHA or with tetanus toxoid.

\section{Cytokine analysis}

The quantification of the cytokines interleukin (IL)-1 $\beta$, IL-2, IL-4, IL-5, IL-6, IL-8, IL-10, IL-12(p40), IL-13, granulocte monocyte-colony stimulating factor (GM-CSF), interferon gamma (IFN- $\gamma$ ), and tumor necrosis factor alfa (TNF- $\alpha$ ) were assessed using human multiplexing bead immunoassays (Biosource Laboratories, Inc.; Hercules, CA) that are based on a sandwich immunoassay that utilize the Luminex ${ }^{\mathrm{TM}}$ fluorescent-bead-based technology and were performed in concordance with the manufacturer's instructions. Briefly, $50 \mu \mathrm{L}$ of stimulated cell supernatant were incubated with antibody-coupled beads. After a series of washes, a biotinylated detection antibody was added to the beads, and the reaction mixture was detected by the addition of streptavidin-phycoerythrin. The components in each well were drawn up into a flow-based Luminex ${ }^{\mathrm{TM}} 100$ suspension array system array system (Bio-Plex 200; Bio-Rad Laboratories, Inc.), which identified and quantitated each specific reaction based on bead color and fluorescence. Unknown supernatant sample cytokine concentrations were calculated by Bio-Plex Manager software using a standard curve derived from the known standard reference cytokine concentrations supplied by the manufacturer. A five-parameter model was used to calculate final concentrations and values are expressed in $\mathrm{pg} / \mathrm{ml}$. The sensitivity of this assay allowed the detection of cytokine concentrations within the following ranges: IL-1 $1315-6810 \mathrm{pg} / \mathrm{ml}$; IL-2 6-7160 pg/ml; IL-4 5-4910 pg/ml; IL-5 3-5390 pg/ml; IL-6 3-5200 pg/ml; IL-8 36330 pg/ml; IL-10 5-4550 pg-ml; IL-12p40 15-6000 pg/ml; IL-13 10-4440 pg/ml; GMCSF $15-9940 \mathrm{pg} / \mathrm{ml} ;$ IFN- $\gamma$ 5-4740 pg/ml, and TNF- $\alpha 10-11390 \mathrm{pg} / \mathrm{ml}$. Concentrations obtained below the sensitivity limit of detection (LOD) of the method were calculated as LOD/2 for statistical comparisons. Values obtained from the reading of samples that exceeded the upper limit of the sensitivity method were further diluted and cytokine concentrations calculated accordingly. Culture supernatants had not undergone any previous freeze/thaws cycle. 


\section{Analysis of cell surface markers by flow cytometry}

Cells were cultured for 24 hours in the presence or absence of $10 \mu \mathrm{g} / \mathrm{mL}$ PHA. Cells were harvested after culture and were washed three times in FACS buffer (PBS, 1\% fetal bovine serum albumin (VWR, USA) and $0.1 \%$ sodium azide (Sigma), before being resuspended and stained in $100 \mu \mathrm{l}$ FACS buffer containing either the following monoclonal antibodies fluorescein isothiocyanate (FITC)-conjugated mouse anti-human CD134, CD25, CD69, CD95; phycoerythrin (PE)-conjugated mouse anti-human CD137, HLA-DR; phycoerythrin (PE)-Cy5-conjugated mouse anti-human CD3; and allophycocyanin (APC)-conjugated mouse anti-human CD4, CD8 (all antibodies were from BD Biosciences, CA, USA). FITCconjugated mouse anti-human GITR was obtained from R and D Systems (Minneapolis, $\mathrm{MN}$ ). Appropriate $\mathrm{IgG}$ isotype controls (BD bioscience) were used to correct for compensation issues. Cells were incubated at $4^{\circ} \mathrm{C}$ for 30 minutes before being spun down and washed with staining buffer. Cells were then analyzed on a LSR II flow cytometer (BD Immunocytometry Systems). The data acquired were analyzed with FlowJo software (BD Immunocytometry Systems). In brief, lymphocytes were gated using forward scatter and side scatter parameter as an indication of cell size and granularity in order to exclude noncellular debris. $\mathrm{CD}^{+}$cells were gated on for analysis of cell surface activation marker expression with further analysis of CD4 and CD8 expression where each parameter was measured separately on $\mathrm{CD}^{+}$populations, $\mathrm{CD}^{+}{ }^{+} \mathrm{CD} 4^{+}$populations and $\mathrm{CD} 3{ }^{+} \mathrm{CD} 8^{+}$ populations. For experiments involving flow cytometric evidence of cellular activation 29 ASD children median age 3.8 years (interquartile range 3.3.-4.3), 27 males and 38 controls 3.4 years (interquartile range $2.8-4.5$ ), 29 males were included.

\section{Statistical Analysis}

In primary analyses, cellular proliferation, induced cytokine levels, and cellular activation markers (outcome) were compared by group (predictor) and statistical significance was determined using a non-parametric Mann-Whitney U test, with a p-value of less than 0.05 considered significant. For the cytokines this analysis was applied to a subset of cytokines that have complete data or had the majority $(>50 \%)$ of PHA-inducible cytokine values that fell above the detection limit (DL) per group (Table 1). Secondary analyses examined the association between induced S.I. or cytokine levels (predictor) and behavioral assessment scores were performed among children with ASD by Spearman's rank correlations (rho). Using clinical characteristics reported in the Early Development Questionnaire and answers to questions regarding loss of language (Q11) and social skills (Q25) of the ADI-R, the autism population was further divided into two groups based on the clinical onset of autistic symptoms; namely, children who regressed in acquired language or social skills after initial typical development, and secondly, children who did not regress. There were too few subjects with other clinical features such as gastrointestinal symptoms or sleep disorders to determine differences between cytokine production or S.I. Multiple comparisons were adjusted for by using the Benjamini-Hochberg False Discovery Rate. All analyses were carried out using SAS version 9.1 (SAS Inc.; Cary, NC) and Prism 5 Software (GraphPad Software; San Diego, CA).

\section{Results}

\section{Proliferative responses to stimulation with PHA but not tetanus are significantly elevated in children with ASD}

$\left[{ }^{3} \mathrm{H}\right]$ thymidine incorporation was used to measure the proliferation of PBMC from 37 ASD and 35 TD children following stimulation with PHA and tetanus (Figure 1). There were no significant differences in proliferation between the two groups when cells were incubated in media alone, median counts were $4,388 \mathrm{cpm}$, interquartile range $(2,109-6,249 \mathrm{cpm})$ for children with ASD and median 4,700 cpm, interquartile range $(3,085-7,147 \mathrm{cpm})$ for TD 
controls. Children with ASD were found to have significantly increased, approximately twofold higher stimulation index (S.I.) following stimulation with PHA compared with TD controls $(p=0.001$, Figure 1). Increased S.I. after PHA stimulation in children with ASD was associated with more impaired behavioral scores when assessed using the ABC such that increased responses were associated with more lethargy $(\mathrm{rho}=0.359, p=0.03)$ and more hyperactivity (rho $=0.361, p=0.03$ ). There were no significant differences in S.I. after PHA stimulation between children with ASD who had developmental regression $(\mathrm{n}=19)$ and those who did not $(\mathrm{n}=18)$, with both groups showing increased responses compared with TD controls $(p<0.02)$. In contrast, there was a trend for decreased recall responses to tetanus in children with ASD, median S.I. 1.34, interquartile range (0.45-2.58), compared with TD controls, median S.I. 2.17, interquartile range (1.13-3.28), but this did not reach statistical significance $(p=0.14)$. It must be noted that all children in this study were up-to-date with their vaccination schedules and the numbers of DTaP (containing tetanus toxoid) vaccinations were similar in both groups.

\section{Altered cytokine responses following stimulation in ASD children}

Cytokine production was measured in supernatants harvested from the PHA-stimulated, tetanus-stimulated, and unstimulated PBMC cultures. The results are summarized in Table 1 where median levels (and interquartile ranges) are provided for each protein. Cytokine production by PBMC following culture in media alone was similar in both ASD and TD groups except for the production of IL-8. Observed levels of the cytokine IL-8 were increased in children with ASD compared with TD controls following PBMC culture in media alone ( $p=0.007$, Table 1). After PHA-stimulation, production of the cytokines GMCSF, IFN $\gamma$, IL-5, IL-6, IL-8, IL-10, IL-12 (p40), IL-13, TNF $\alpha$ were measured with sufficient accuracy and reproducibility above the detection limit (DL). Details are summarized in Table 1 and Figure. 2. Following stimulation with PHA there was a greater than seven-fold increase in the production of GM-CSF in ASD cell cultures compared with TD controls ( $p=$ 0.0001 , Table 1, Figure 2). In addition, TNF $\alpha$ production was increased nearly four-fold in ASD cell cultures compared with TD ( $p=0.027$, Table 2, Figure 2). Production of IL-13 following PHA-stimulation was more than doubled in ASD cell cultures compared with TD $(p=0.007$, Table 1, Figure 2). There was also a trend for increased IL-5 production in ASD cultures but this did not reach statistical significance. In contrast, there was a greater than $30 \%$ decrease of IL-12p40 production after PHA-stimulation in ASD cell cultures compared with TD controls $(p=0.04$, Table 1$)$.

We then examined whether there were associations between cytokine levels and the severity of clinical behavioral outcomes. Based on ADI-R assessment scores in the children with ASD, more stereotyped behaviors were associated with increased TNF $\alpha$ (rho $=0.381, p=$ $0.01)$ and increased IFN $\gamma(\mathrm{rho}=0.463, p=0.002)$. There was also a significant association between more impaired communication, as measured by ADOS, and increased IFN $\gamma$ production ( $($ ho $=0.499, p=0.005)$ and increased IL-8 production ( rho $=0.460, p=0.02)$. Increased IL-12p40 was associated with higher reports (worsening) of inappropriate speech (rho $=0.361, p=0.03)$ and increased hyperactivity (rho $=0.333, p=0.04)$ as assessed by $\mathrm{ABC}$. These data collectively suggest that pro-inflammatory or $\mathrm{T}_{\mathrm{H}} 1$ cytokines are associated with more impaired (worse) behaviors in children with ASD. In contrast, increased IL-13 was associated with lower scores or less hyperactivity (rho $=-0.36, p=0.02$ ) as assessed by the ABC. Assessment of developmental performance, measured by MSEL, showed that production of IL-10 was associated with better expressive language (rho $=0.461, p=0.004$ ) and increased IL-5 was associated with better fine motor skills (rho $=0.44, p=0.008$ ), better visual reception ( $r$ ro $=0.34, p=0.04$ ) and more expressive language (rho $=0.324, p=0.05$ ). These data suggest that increased $\mathrm{T}_{\mathrm{H}} 2$ responses are associated with better developmental function and behavioral responses in children with ASD. Moreover, increased GM-CSF 
production was associated with better adaptive scores for socialization ( $r h o=0.353, p=$ 0.02 ) as assessed by VABS and lower scores or less lethargy (rho $=-0.318, p=0.05$ ) as assessed by ABC. There were no significant differences in cytokine levels between children with ASD who had developmental regression reported and those that did not, with both groups showing similar differences compared with TD controls. In addition, associations between cytokines and behaviors were similar in both the children with ASD who had regressed and children with ASD that had not regressed.

Recall cytokine responses to tetanus toxoid were largely unchanged in ASD cell cultures compared with those from TD controls (data not shown), with the exception of IFN $\gamma$ production, which was significantly decreased after tetanus stimulation in children with ASD, median 5, interquartile range (5-6.6) compared with TD controls, median 9.1, interquartile range $(5.4-31.1),(p=0.005)$.

\section{Partial or altered patterns of activation in T cells in ASD children}

Having observed increased proliferative responses and cytokine production following stimulation with PHA in children with ASD, we investigated if there was evidence of increased cellular activation and upregulation of cell surface expression of activation markers on T cells following PHA stimulation, in 29 children with ASD and 38 TD controls, using flow cytometry (Table 2). There were no significant differences in the proportions of $\mathrm{CD}^{+}, \mathrm{CD}^{+}$and $\mathrm{CD}^{+} \mathrm{T}$ cells between children with ASD and TD control samples in either unstimulated or stimulated conditions as has previously been shown (Onore et al., 2009).

The frequency of $\mathrm{T}$ cells expressing cell surface markers of activation in unstimulated media alone culture conditions were similar in children with ASD compared with TD controls with the exception of decreased frequencies of $\mathrm{CD}^{+} \mathrm{GITR}^{+} \mathrm{T}$ cells $(p=0.001$; Table 2$)$ and $\mathrm{CD}^{+} \mathrm{GITR}^{+} \mathrm{T}$ cells $(p=0.043$; Table 4$)$ in ASD. There was also a trend for decreased frequencies of $\mathrm{CD}^{+}{ }^{+} \mathrm{GITR}^{+} \mathrm{T}$ cells in children with ASD compared with controls but this did not reach significance $(p=0.06$; Table 3$)$.

Following stimulation with PHA, the expression of cell activation markers CD69 and HLA$\mathrm{DR}$ on $\mathrm{CD}^{+}, \mathrm{CD}^{+}$and $\mathrm{CD}^{+} \mathrm{T}$ cells were similar in each group (Table 2, 3, and 4, respectively). However, there was a decrease in the frequency of $\mathrm{CD}^{+} \mathrm{T}$ cells that expressed the activation markers CD134 $(p=0.0001)$ and CD25 $(p=0.03)$ following PHA stimulation in children with ASD compared with controls (Table 2). There were also decreased frequencies of T helper CD4 ${ }^{+}$cells expressing CD134 $(p=0.005)$ and CD25 $(p=$ 0.02 ) in children with ASD compared with controls (Table 3 ). Of the CD ${ }^{+} \mathrm{T}$ cell subset, there was a decrease in the frequency of cells expressing CD134 $(p=0.005)$ and CD25 $(p=$ $0.008)$ but an increase of CD8 ${ }^{+} \mathrm{T}$ cells expressing CD137 $(p=0.008)$ following PHA stimulation in children with ASD compared with controls (Table 4). There were no significant differences in cell activation markers between children with ASD who regressed and those who did not, with both groups showing similar differences compared with TD controls.

\section{Discussion}

Findings from our current study describe the differential sensitivity of the adaptive immune response after in vitro immunological challenge in 2-5 year old children with ASD compared with age-matched TD control children. Our results demonstrate increased proliferative responses and notable differences in cytokine production and cell surface expression of activation markers following PHA stimulation in children with ASD. Altered cytokine production included increased production of GM-CSF and TNF $\alpha$ (7.4-, and 3.5fold increases, respectively) following PHA stimulation in children with ASD relative to TD controls. In addition, there was an almost 2.2-fold increase in IL-13 production following 
PHA stimulation in children with ASD, while in contrast the production of IL-12p40 was decreased significantly (approximately 35\%). This suggests a possible skewing towards a $\mathrm{T}_{\mathrm{H}} 2$ (IL-13) profile and away from $\mathrm{T}_{\mathrm{H}} 1$ (IL-12p40) profile in children with ASD relative to TD controls. Moreover, we found associations between pro-inflammatory (TNF $\alpha, \mathrm{IL}-8)$ and $\mathrm{T}_{\mathrm{H}} 1$ (IFN $\gamma$ ) cytokine production and severity of certain core measures of ASD as assessed by ADI-R (IFN $\gamma, \mathrm{TNF} \alpha$ ) and ADOS (IFN $\gamma$, IL-8), as well as aberrant behaviors as measured by $A B C$ (IL-12p40), such that as these cytokine levels increased, impairments in behavior were more pronounced. In contrast, increased production of $\mathrm{T}_{\mathrm{H}} 2$ cytokines were associated with better behavior scores as assessed by ABC (IL-13) as well as better developmental scores as assessed by MSEL (IL-10, IL-5). Production of GM-CSF was associated with improved adaptive outcomes as assessed by VABS, as well as fewer aberrant behaviors. At present it is unclear how cytokine production can affect behavioral and developmental outcomes during childhood in ASD, but our data suggest that $\mathrm{T}_{\mathrm{H}} 1$ skewing may be associated with more impaired behaviors whereas $\mathrm{T}_{\mathrm{H}} 2$ responses may be associated with improved developmental and adaptive function in ASD. Further validation of the associations observed here between cytokine production and behaviors is necessary; however, these results may have important implications in the design and monitoring of treatments targeted for children with ASD.

Our current findings are consistent with previous studies that have shown a $\mathrm{T}_{\mathrm{H}} 2$ skewing after stimulation in children with ASD (Molloy et al., 2005; Gupta et al., 1998). Increasing evidence suggests that neurogenesis is modulated by the interaction between T cells and CNS-microglia cells; too little immune activity may impair neurogenesis and alter cognition (Ziv et al., 2006; Ziv and Schwartz, 2008; Kipnis et al., 2004). Moreover, a key role for IL-4 producing $T$ cells in the regulation of cognitive function has been described and suggests an important role for $\mathrm{T}_{\mathrm{H}} 2$ cells in cognition and possibly other behaviors (Derecki et al., 2010). Of note, increased production of the $\mathrm{T}_{\mathrm{H}} 2$ cytokine IL-13 in our study of children with ASD was associated with improvement in aberrant behaviors and better developmental and adaptive function, suggesting that a skew towards $\mathrm{T}_{\mathrm{H}} 2$ responses may be beneficial in ASD and is compatible with the hypothesis that $\mathrm{T}_{\mathrm{H}} 2$ cells play a critical role in neuronal function. Recently it was shown that aberrant behaviors in some children with ASD improve during episodes of fever but return to baseline after the child recovers (Curran et al., 2007). Together these data suggest that immune activation, including activation of T-lymphocyte subsets, may be important in modulating and potentially improving behaviors in some individuals with autism.

Our findings, for the first time, show that GM-CSF production is greatly increased in children with ASD following PHA stimulation when compared with controls. GM-CSF is a growth factor that stimulates growth and differentiation of myelomonocytic progenitor cells in the bone marrow into monocytes and dendritic cells (DC) and, thus, has an important function in increasing innate immune cell numbers during infections (Hamilton and Anderson, 2004). GM-CSF is also thought to play a role in autoimmunity and has been shown to enhance $\mathrm{T}_{\mathrm{H}} 17$ cell development (Sonderegger et al., 2008). Recently, CD8+ T cells producing GM-CSF were demonstrated to play an important role in the generation of "effector" DC that are key regulators of innate and adaptive responses (Min et al., 2010). Moreover, GM-CSF has been shown to upregulate neuronal receptors on CD34 ${ }^{+}$ hematopoietic stem progenitor cells enhancing responses to neurotransmitters (Kalinkovich et al., 2009). In addition, GM-CSF can cross the blood-brain barrier (McLay et al., 1997) and can stimulate neurite growth and promote axonal regeneration (Brook et al., 1998; Kannan et al., 2000). GM-CSF also promotes neuronal differentiation of adult neuronal stem cells and acts as a neuronal growth factor in the brain (Schabitz et al., 2007; Kruger et al., 2007). Thus, increased GM-CSF production in ASD after immunological challenge may have a number of significant roles on both immunodevelopment as well as 
neurodevelopment in children with ASD that warrant further investigation. Interestingly, the increased production of GM-CSF was associated with improved developmental outcomes and better (fewer) aberrant behaviors in ASD and may suggest a role for GM-CSF in the improvement of cognition and adaptive function in ASD. On the other hand, GM-CSF receptors are present on microglia, astrocytes, neurons and oligodendrocytes; the blockade of GM-CSF receptors with anti-GM-CSF antibodies suppresses microglia activity (Reddy et al., 2009). As marked microglia cell activation is a prominent feature of ASD (Vargas et al., 2005), as well as other neuroinflammatory conditions such as Alzheimer's disease and multiple sclerosis, blocking GM-CSF receptors and thus microglia responses may have important anti-inflammatory effects and implications for therapy. Further investigation of the role of GM-CSF in immune responses and neurodevelopment in ASD is warranted.

In the present study, we observed significantly increased cellular proliferative responses in response to PHA stimulation but not tetanus in children with ASD compared with controls. One previous study demonstrated a decreased response to PHA stimulation in older children with ASD (Stubbs and Crawford, 1977). However, there are a number of considerable differences between the studies in experimental design and the data presented. Importantly, in the Stubbs and Crawford study, the number of "autism" cases is low $(n=12)$ and there is insufficient information regarding diagnosis that does not necessarily correspond to the stricter criteria used today, to quote "the referral question usually centered around whether the child had autism" and was not performed using DSM-III, or -IV criteria. Readout values of ${ }^{3} \mathrm{H}$ thymidine counts per minute were considerably lower than in our study following stimulation and ranged from $0.028-0.074 \mathrm{cpm}$, likely due to the almost homeopathic concentrations of PHA used $(0.06 \mu \mathrm{g} / \mathrm{ml})$ and the longer culture time of 5 days. Further inconsistencies between the studies may relate to the age of subjects and biological changes that may occur throughout the course of the disorder, or that the data is reflective of the possibility that ASD represents a spectrum of clinically related disorders, each with differing underlying pathologies. Decreased responses to teatanus could stem from abnormalities in antigen presenting cells (APC) as tetanus toxoid needs to be first phagocytosed/pinocytosed before it can be presented to and detected by $\mathrm{T}$ cells with the appropriate $\mathrm{T}$ cell receptors. Antigen uptake and/or presentation may be altered in ASD and thus may leads to a decreased proliferative responses following tetanus toxoid stimulation. We have previously published that are abnormalities in APC such as monocytes in ASD (Enstrom et al., 2010). In contrast, PHA provides a more direct stimulation of T cells and circumvents the need for presentation by APC. These findings require further investigation.

Following stimulation, T cells produce and use IL-2 in an autocrine fashion which is required to drive proliferation of T cells (Smith, 1988). Expression of CD25 (the IL-2 receptor alpha chain) on T cells can be used as a marker for cell activation as it is not generally expressed on unstimulated cells, but is upregulated in response to stimulation (Poulton et al., 1988). The frequency of $\mathrm{CD}^{+}, \mathrm{CD}^{+}$and $\mathrm{CD} 8^{+} \mathrm{T}$ cells expressing $\mathrm{CD} 25$ was investigated using flow cytometry to determine whether there were changes of this activation marker. There was a significant decrease in the frequency of $\mathrm{CD}^{+}, \mathrm{CD}^{+}$and $\mathrm{CD}^{+} \mathrm{T}$ cells expressing CD25 after PHA-stimulation in children with ASD compared with controls. In contrast, expression of early and late markers of activation (CD69 and HLA-DR, respectively), on $\mathrm{CD}^{+} \mathrm{T}$ cells and, $\mathrm{CD} 4^{+}$and $\mathrm{CD} 8^{+} \mathrm{T}$ cells subsets after stimulation was not different in children with ASD compared with controls. This profile may suggest an altered activation of T cells in ASD and is consistent with previous findings of reduced frequency of CD25 expressing T cells, but not HLA-DR expressing T cells, in ASD (Denney et al., 1996; Plioplys et al., 1994; Mostafa et al., 2009). No differences were observed in IL-2 production between ASD and TD children (data not shown). 
The expression of $\mathrm{CD} 25^{+}$on $\mathrm{T}$ cells is primarily a marker of cell activation but also contained within the population of $\mathrm{CD} 25^{+} \mathrm{T}$ cells is a subset of regulatory $\mathrm{T}$ cells (Sakaguchi et al., 2010). There are many different types of regulatory $\mathrm{T}$ cells that act to control or limit immune responses and help in the resolution of inflammation (Shevach, 2006). T regulatory cells are thought to derive either as a separate lineage from the thymus that are present at birth and often termed natural $\mathrm{T}$ regs or, are derived from previously activated $\mathrm{T}$ cells that after a number of cell divisions either gain, or can be induced, to have regulatory functions. These cells are often termed adaptive or induced T regs (Akbar et al., 2007). Previous work by our group and others has shown that in children with ASD there is a decrease in the regulatory cytokine TGF $\beta 1$ that is produced by different types of regulatory $\mathrm{T}$ cells, and decreases in the frequencies of the $\mathrm{CD}^{+} \mathrm{IL}-10^{+} \mathrm{T}$ cell subset that may reflect changes in the ability of specific types of $\mathrm{T}$ regs to control immune responses in ASD (Ashwood et al., 2004; Ashwood et al., 2006a; Ashwood et al., 2008; Jyonouchi et al., 2001; Molloy et al., 2005; Okada et al., 2008). In this study we showed that there was a decrease in the frequency of T cells that expressed GITR, another putative marker of regulatory $\mathrm{T}$ cells, in unstimulated cultures from children with ASD compared to controls. Moreover, the inability to express CD25, but not CD69 and HLA-DR, after stimulation in children with ASD may point to the differential activation of "effector" T cells and away from the generation of adaptive $\mathrm{T}$ regulatory cells that express CD25. This may suggest that the generation of adaptive $\mathrm{T}$ regs and not naturally occurring $\mathrm{T}$ regs is suboptimal in ASD. The lack of a controlling influence by regulatory $\mathrm{T}$ cells could contribute to the increased cytokine production and proliferative responses that was observed after stimulation in children with ASD. Unfortunately, many of the same cell surface markers are present on activated as well as natural and adaptive $\mathrm{T}$ regs, including $\mathrm{CD} 25^{+}$, and at present it is difficult to distinguish the various subtypes. Thus far, there is no published data on $\mathrm{T}$ regulatory cells in ASD and further work to characterize these cells is needed.

In this study we also saw decreased frequencies of $\mathrm{CD}^{+}, \mathrm{CD}^{+}$and $\mathrm{CD} 8^{+} \mathrm{T}$ cell expressing the co-stimulatory molecule CD134 (also known as OX40) after stimulation in children with ASD relative to controls. CD134 is a member of the TNFR superfamily of receptors and is not constitutively expressed on resting naïve $\mathrm{T}$ cells but is expressed following activation. CD134 ligation has a critical role in the maintenance of the immune response and the development towards a memory response due to its ability to enhance cell survival (Croft, 2003; Song et al., 2005). Decreased CD134 may therefore suggest an altered ability in memory $\mathrm{T}$ cell expansion or $\mathrm{T}$ cell survival after stimulation and could affect the ability of children with ASD to mount long-term or memory immune response to antigens. Reduced global immunoglobulin (Ig) production as well as reduced specific Ig responses to specific antigens including rubella vaccination have been described in ASD (Heuer et al., 2008; Stubbs, 1976) and may be due to altered memory T cell mediated help of B cells that could stem from reduced CD134 expression. Another member of the TNF receptor family is CD137 (also known as 4-1BB), which is a co-stimulatory molecule expressed by activated $\mathrm{T}$ cells, to a larger extent on $\mathrm{CD} 8^{+}$rather than on $\mathrm{CD}^{+} \mathrm{T}$ cells. $\mathrm{CD} 137$ engagement by CD137L enhances T cell proliferation, effector functions, and survival (Arch and Thompson 1998; Cooper et al., 2002). After stimulation there was an increased frequency of $\mathrm{CD} 137^{+} \mathrm{CD} 8^{+} \mathrm{T}$ cells in ASD children compared to controls, and may suggest potential differential activation of this T cell subset. Of interest, both CD134 and CD137 are expressed on regulatory $\mathrm{T}$ cells and ligation of these receptors has been shown to have major roles both positively and negatively in the generation of regulatory $\mathrm{T}$ cells and regulatory cytokine activity (So et al., 2008). Moreover, the ligand for CD137 is present on monocytes and delivers an activating signal via reverse signaling, that induces potent changes from monocyte activity to DC activity (Kwajah and Schwarz, 2010). Notably, CD137-generated DCs are more potent than other classically in vitro derived DCs for inducing T cell proliferation. Furthermore, CD137-generated DCs inhibit the development of regulatory T 
cells while promoting T cell expression of perforin and IL-13 (Kwajah Kwajah and Schwarz, 2010). The findings of increased production of GM-CSF when coupled with the increased presence of $\mathrm{CD} 137^{+} \mathrm{CD} 8^{+} \mathrm{T}$ cells in ASD may suggest that there is an environment that conspires to the differential generation of DCs or skewed DC populations/ function, and reduced regulatory T cell development/function in ASD, which may help explain some of the findings observed in this study such as increased IL-13 production and cellular proliferation.

The aim of the present study was to identify differences in dynamic cellular immune responses between children with ASD and typically developing controls. ASD is a clinically heterogeneous disorder with a spectrum of symptoms, yet clear and significant differences in $\mathrm{T}$ cell responses can be identified in these children. Increased proliferative responses, increased production of GM-CSF, IL-13, and TNF $\alpha$, reduced IL-12p40, and alterations in the frequencies of $\mathrm{T}$ cell subpopulations expressing CD25, CD134 and CD137 all suggest an acquired immune response phenotype that promotes cellular activation. In addition, we found associations between stimulation induced cytokines production and the severity of behaviors in children with ASD, such that pro-inflammatory/ $\mathrm{T}_{\mathrm{H}} 1$ cytokines were associated with more behavioral impairment, whereas GM-CSF and $\mathrm{T}_{\mathrm{H}} 2$ cytokine production was associated with better developmental and adaptive function. Although these data should be treated with caution until further validation can be performed, it should be noted that a number of other studies have shown that impairments in core ASD features as well as aberrant behaviors, are associated with altered immune profiles (Ashwood et al., 2008; Ashwood et al., 2010; Grigorenko et al., 2008; Tsuchiya et al., 2007; Enstrom et al., 2009c; Enstrom et al., 2010; Onore et al., 2009). Together these observations may indicate that dysfunctional cellular immune responses in ASD can modulate behaviors and core features of ASD. The potential separation of ASD into subgroups based on immunological parameters may have important implications for both diagnosis and therapeutic manipulation. Further validation of the links between behavior and immune function in ASD are necessary, including analysis of frequently observed co-morbidities of gastrointestinal problems, seizures, macrocephaly, cognitive impairments, and sleep disorders. More extensive longitudinal studies will be required to characterize the immunological changes associated with the disorder and severity of behavioral symptoms. Taken together our data demonstrate compelling evidence for immune cellular dysfunction in ASD and the mechanisms of this and how it changes throughout disease progression need to be pinpointed in order to further elucidate our understanding of this disorder.

\section{Acknowledgments}

This study was funded by the NIEHS Children's Center grant (P01 ES011269), US EPA STAR program grant (R833292 and R829388), NIEHS CHARGE study (R01ES015359), Autism Speaks Foundation, Peter Emch Foundation, HEDCO foundation, The Boler Company Foundation and the Johnson Foundation. We would like to thank and the staff of both the UC Davis M.I.N.D Institute and the CHARGE study, and Christina Kwong and Angela Tarver for their technical support. The commitment of the families who took part in these studies is gratefully acknowledged.

\section{References}

Akbar AN, Vukmanovic-Stejic M, Taams LS, Macallan DC. The dynamic co-evolution of memory and regulatory CD4+ T cells in the periphery. Nat Rev Immunol. 2007; 7(3):231-7. [PubMed: 17318234]

American Psychiatric Association. Diagnostic and Statistical Manual of Mental Disorders DSM-IVTR. 4. American Psychiatric Association Publishing Inc; Washington DC, USA: 2000. 
Arch RH, Thompson CB. 4-1BB and Ox40 are members of a tumor necrosis factor (TNF)-nerve growth factor receptor subfamily that bind TNF receptor-associated factors and activate nuclear factor kappaB. Mol Cell Biol. 1998; 18(1):558-565. [PubMed: 9418902]

Ashwood P, Anthony A, Torrente F, Wakefield AJ. Spontaneous mucosal lymphocyte cytokine profiles in children with autism and gastrointestinal symptoms: Mucosal immune activation and reduced counter regulatory interleukin-10. J Clin Immunol. 2004; 24(6):664-673. [PubMed: 15622451]

Ashwood P, Wakefield AJ. Immune activation of peripheral blood and mucosal CD3+ lymphocyte cytokine profiles in children with autism and gastrointestinal symptoms. J Neuroimmunol. 2006; 173(1-2):126-134. [PubMed: 16494951]

Ashwood P, Wills S, Van de Water J. The immune response in autism: a new frontier for autism research. J Leukoc Biol (2006). 2006; 80(1):1-15.

Ashwood P, Enstrom A, Krakowiak P, Hertz-Picciotto I, Hansen RL, Croen LA, Ozonoff S, Pessah IN, Van de Water J. Decreased transforming growth factor $\beta 1$ in autism: A potential link between immune dysregulation and impairment in clinical behavioral outcomes. J Neuroimmunol. 2008; 204(1-2):149-153. [PubMed: 18762342]

Ashwood P, Krakowiak P, Hertz-Picciotto I, Hansen R, Pessah I, Van de Water J. Elevated plasma cytokines in autism spectrum disorders provide evidence of immune dysfunction and are associated with impaired behavioral outcome. Brain Behav Immun. 2010 (in press).

Atladóttir HO, Pedersen MG, Thorsen P, Mortensen PB, Deleuran B, Eaton WW, Parner ET. Association of family history of autoimmune diseases and autism spectrum disorders. Pediatrics. 2009; 124(2):687-94. [PubMed: 19581261]

Atladóttir HO, Thorsen P, Schendel DE, Østergaard L, Lemcke S, Parner ET. Association of hospitalization for infection in childhood with diagnosis of autism spectrum disorders: a Danish cohort study. Arch Pediatr Adolesc Med. 2010; 164(5):470-7. [PubMed: 20439799]

Barker V, Middleton G, Davey F, Davies AM. TNF $\alpha$ contributes to the death of NGF-dependent neurons during development. Nat Neurosci. 2001; 4(12):1194-1198. [PubMed: 11685224]

Brook GA, Plate D, Franzen R, Martin D, Moonen G, Schoenen J, Schmitt AB, Noth J, Nacimiento W. Spontaneous longitudinally orientated axonal regeneration is associated with the Schwann cell framework within the lesion site following spinal cord compression injury of the rat. J Neurosci Res. 1998; 53:51-65. [PubMed: 9670992]

Cacci E, Ajmone-Cat MA, Anelli T, Biagioni S, Minghetti L. In vitro neuronal and glial differentiation from embryonic or adult neural precursor cells are differently affected by chronic or acute activation of microglia. Glia. 2008; 56(4):412-425. [PubMed: 18186084]

Cabanlit M, Wills S, Goines P, Ashwood P, Van de Water J. Brain-specific autoantibodies in the plasma of subjects with autistic spectrum disorder. Ann NY Acad Sci. 2007; 1107:92-103. [PubMed: 17804536]

Campbell DB, D’Oronzio R, Garbett K, Ebert PJ, Mirnics K, Levitt P, Persico AM. Disruption of cerebral cortex MET signaling in autism spectrum disorder. Ann Neurol. 2007; 62(3):243-250. [PubMed: 17696172]

Campbell DB, Sutcliffe JS, Ebert PJ, Militerni R, Bravaccio C, Trillo S, Elia M, Schneider C, Melmed $\mathrm{R}$, Sacco R, Persico AM, et al. A genetic variant that disrupts MET transcription is associated with autism. Proc Natl Acad Sci U S A. 2006; 103(45):16834-16839. [PubMed: 17053076]

Chez MG, Dowling T, Patel PB, Khanna P, Kominsky M. Elevation of tumor necrosis factor-alpha in cerebrospinal fluid of autistic children. Pediatr Neurol. 2007; 36(6):361-5. [PubMed: 17560496]

Comi AM, Zimmerman AW, Frye VH, Law PA, Peeden JN. Familial clustering of autoimmune disorders and evaluation of medical risk factors in autism. J Child Neurol. 1999; 14(6):388-394. [PubMed: 10385847]

Cooper D, Bansal-Pakala P, Croft M. 4-1BB (CD137) controls the clonal expansion and survival of CD8 T cells in vivo but does not contribute to the development of cytotoxicity. Eur J Immunol. 2002; 32(2):521-9. [PubMed: 11828369]

Connolly AM, Chez M, Streif EM, Keeling RM, Golumbek PT, Kwon JM, Riviello JJ, Robinson RG, Neuman RJ, Deuel RM. Brain-derived neurotrophic factor and autoantibodies to neural antigens in 
sera of children with autistic spectrum disorders, Landau-Kleffner syndrome, and epilepsy. Biol Psychiatry. 2006; 59(4):354-363. [PubMed: 16181614]

Croen LA, Grether JK, Yoshida CK, Odouli R, Van de Water J. Maternal autoimmune diseases, asthma and allergies, and childhood autism spectrum disorders: a case-control study. Arch Pediatr Adolesc Med. 2005; 159(2):151-157. [PubMed: 15699309]

Croft M. Co-stimulatory members of the TNFR family: keys to effective T-cell immunity? Nat Rev Immunol. 2003; 3(8):609-20. [PubMed: 12974476]

Curran LK, Newschaffer CJ, Lee LC, Crawford SO, Johnston MV, Zimmerman AW. Behaviors associated with fever in children with autism spectrum disorders. Pediatrics. 2007; 120:e13861392. [PubMed: 18055656]

Denney DR, Frei BW, Gaffney GR. Lymphocyte subsets and interleukin-2 receptors in autistic children. J Autism Dev Disord. 1996; 26(1):87-97. [PubMed: 8819772]

Derecki NC, Cardani AN, Yang CH, Quinnies KM, Crihfield A, Lynch KR, Kipnis J. Regulation of learning and memory by meningeal immunity: a key role for IL-4. J Exp Med. 2010; 207(5):106780. [PubMed: 20439540]

Enstrom AM, Van de Water JA, Ashwood P. Autoimmunity in autism. Curr Opin Investig Drugs. 2009a; 10:463-473.

Enstrom AM, Lit L, Onore CE, Gregg JP, Hansen RL, Pessah IN, Hertz-Picciotto I, Van de Water JA, Sharp FR, Ashwood P. Altered gene expression and function of peripheral blood natural killer cells in children with autism. Brain Behav Immun. 2009b; 23(1):124-133. [PubMed: 18762240]

Enstrom A, Krakowiak P, Onore C, Pessah IN, Hertz-Picciotto I, Hansen RL, Van de Water JA, Ashwood P. Increased IgG4 levels in children with autism disorder. Brain Behav Immun. 2009c; 23:389-395. [PubMed: 19136055]

Enstrom A, Onore C, Van de Water J, Ashwood P. Differential monocyte responses to TLR ligands in children with autism spectrum disorders. Brain Behav Immun. 2010; 24(1):64-71. [PubMed: 19666104]

Gadient RA, Patterson PH. Leukemia inhibitory factor, interleukin 6, and other cytokines using the GP130 transducing receptor: Roles in inflammation and injury. Stem Cells. 1999; 17(3):127-137. [PubMed: 10342555]

Garbett K, Ebert PJ, Mitchell A, Lintas C, Manzi B, Mirnics K, Persico AM. Immune transcriptome alterations in the temporal cortex of subjects with autism. Neurobiol Dis. 2008; 30(3):303-311. [PubMed: 18378158]

Gilmore JH, Jarskog LF, Vadlamudi S. Maternal poly I:C exposure during pregnancy regulates TNF $\alpha$, BDNF, and NGF expression in neonatal brain and the maternal-fetal unit of the rat. $\mathrm{J}$ Neuroimmunol. 2005; 159(1-2):106-112. [PubMed: 15652408]

Grigorenko EL, Han SS, Yrigollen CM, Leng L, Mizue Y, Anderson GM, Mulder EJ, de Bildt A, Minderaa RB, Volkmar FR, Chang JT, Bucala R. Macrophage migration inhibitory factor and autism spectrum disorders. Pediatrics. 2008; 122(2):438-445.

Gupta S, Aggarwal S, Rashanravan B, Lee T. Th1- and Th2-like cytokines in CD4+ and CD8+ T cells in autism. J Neuroimmunol. 1998; 85(1):106-109. [PubMed: 9627004]

Hamilton JA, Anderson GP. GM-CSF Biology. Growth Factors. 2004; 22(4):225-31. [PubMed: 15621725]

Herman GE, Butter E, Enrile B, Pastore M, Prior TW, Sommer A. Increasing knowledge of PTEN germline mutations: Two additional patients with autism and macrocephaly. Am J Med Genet A. 2007; 143:589-593. [PubMed: 17286265]

Hertz-Picciotto I, Croen LA, Hansen R, Jones CR, Van de Water J, Pessah IN. The CHARGE study: an epidemiologic investigation of genetic and environmental factors contributing to autism. Environ Health Perspect. 2006; 114:1119-1125. [PubMed: 16835068]

Heuer L, Ashwood P, Schauer J, Goines P, Krakowiak P, Hertz-Picciotto I, Hansen R, Croen LA, Pessah IN, Van de Water J. Reduced levels of immunoglobulin in children with autism correlates with behavioral symptoms. Autism Res. 2008; 1(5):275-83. [PubMed: 19343198]

Juttler E, Tarabin V, Schwaninger M. Interleukin-6 (IL-6): a possible neuromodulator induced by neuronal activity. Neuroscientist. 2002; 8:268-275. [PubMed: 12061506] 
Jyonouchi H, Sun S, Le H. Proinflammatory and regulatory cytokine production associated with innate and adaptive immune responses in children with autism spectrum disorders and developmental regression. J Neuroimmunol. 2001; 120:170-179. [PubMed: 11694332]

Jyonouchi H, Geng L, Cushing-Ruby A, Quraishi H. Impact of innate immunity in a subset of children with autism spectrum disorders: a case control study. J Neuroinflammation. 2008; 5:52-59. [PubMed: 19025588]

Kalinkovich A, Spiegel A, Shivtiel S, Kollet O, Jordaney N, Piacibello W, Lapidot T. Blood-forming stem cells are nervous: direct and indirect regulation of immature human CD34+ cells by the nervous system. Brain Behav Immun. 2009; 23(8):1059-65. [PubMed: 19341792]

Kannan Y, Moriyama M, Sugano T, Yamate J, Kuwamura M, Kagaya A, Kiso Y. Neurotrophic action of interleukin 3 and granulocyte-macrophage colony-stimulating factor on murine sympathetic neurons. Neuroimmunomodulation. 2000; 8:132-141. [PubMed: 11124579]

Kipnis J, Cohen H, Cardon M, Ziv Y, Schwartz M. T cell deficiency leads to cognitive dysfunction: implications for therapeutic vaccination for schizophrenia and other psychiatric conditions. Proc Natl Acad Sci U S A. 2004; 101:8180-8185. [PubMed: 15141078]

Krüger C, Laage R, Pitzer C, Schäbitz WR, Schneider A. The hematopoietic factor GM-CSF (granulocyte-macrophage colony-stimulating factor) promotes neuronal differentiation of adult neural stem cells in vitro. BMC Neurosci. 2007; 8:88-95. [PubMed: 17953750]

Kwajah MMS, Schwarz H. CD137 ligand signaling induces human monocyte to dendritic cell differentiation. Eur J Immunol. 2010; 40(7):1938-1949. [PubMed: 20432236]

Lee LC, Zachary AA, Leffell MS, Newschaffer CJ, Matteson KJ, Tyler JD, Zimmerman AW. HLADR4 in families with autism. Pediatr Neurol. 2006; 35 (5):303-7. [PubMed: 17074598]

Li X, Chauhan A, Sheikh AM, Patil S, Chauhan V, Li XM, Ji L, Brown T, Malik M. Elevated immune response in the brain of autistic patients. J Neuroimmunol. 2009; 207(1-2):111-116. [PubMed: 19157572]

Lintas C, Sacco R, Garbett K, et al. Involvement of the PRKCB1 gene in autistic disorder: significant genetic association and reduced neocortical gene expression. Mol Psychiatry. 2009; 14:705-718. [PubMed: 18317465]

McLay RN, Kimura M, Banks WA, Kastin AJ. Granulocyte macrophage colony stimulating factor crosses the blood brain and blood spinal cord barriers. Brain. 1997; 120:2083-2091. [PubMed: 9397023]

Mehler MF, Kessler JA. Cytokines in brain development and function. Adv Protein Chem. 1998; 52:223-251. [PubMed: 9917922]

Min L, Mohammad Isa SA, Shuai W, Piang CB, Nih FW, Kotaka M, Ruedl C. Cutting edge: granulocyte-macrophage colony-stimulating factor is the major CD8+ T cell-derived licensing factor for dendritic cell activation. J Immunol. 2010; 184(9):4625-9. [PubMed: 20357255]

Centers for Disease Control and Prevention (CDC). Prevalence of autism spectrum disorders - Autism and Developmental Disabilities Monitoring Network, United States, 2006. Autism and Developmental Disabilities Monitoring Network Surveillance Year 2006 Principal Investigators. MMWR Surveill Summ. 2009; 58(10):1-20.

Molloy CA, Morrow AL, Meinzen-Derr J, Schleifer K, Dienger K, Manning-Courtney P, Altaye M, Wills-Karp M. Elevated cytokine levels in children with autism spectrum disorder. J Neuroimmunol. 2005; 172(1-2):198-205. [PubMed: 16360218]

Molloy CA, Morrow AL, Meinzen-Derr J, Dawson G, Bernier R, Dunn M, Hyman SL, McMahon WM, Goudie-Nice J, Hepburn S, Minshew N, et al. Familial autoimmune thyroid disease as a risk factor for regression in children with autism spectrum disorder: A CPEA study. Journal of Autism and Developmental Disorders. 2006; 36(3):317-324. [PubMed: 16598435]

Mostafa GA, Al Shehab A, Fouad NR. Frequency of CD4+CD25high regulatory T cells in the peripheral blood of Egyptian children with autism. J Child Neurol. 2010; 25(3):328-35. [PubMed: 19713552]

Muhle R, Trentacoste SV, Rapin I. The genetics of autism. Pediatrics. 2004; 113 (5):472-486.

Munoz-Fernandez MA, Fresno M. The role of tumour necrosis factor, interleukin 6, interferon- $\gamma$ and inducible nitric oxide synthase in the development and pathology of the nervous system. Prog Neurobiol. 1998; 56(3):307-340. [PubMed: 9770242] 
Niehus R, Lord C. Early medical history of children with autism spectrum disorders. J Dev Behav Pediatr. 2006; 27 (2 Suppl):S120-7. [PubMed: 16685178]

Okada K, Hashimoto K, Iwata Y, Nakamura K, Tsujii M, Tsuchiya KJ, Sekine Y, Suda S, Suzuki K, Sugihara G, Matsuzaki H, Mori N. Decreased serum levels of transforming growth factor- $\beta 1$ in patients with autism. Prog Neuropsychopharmacol Biol Psychiatry. 2007; 31(1):187-190. [PubMed: 17030376]

Onore C, Krakowiak P, Enstrom A, Hansen R, Hertz-Picciotto I, Van de Water J, Ashwood P. Decreased cellular IL-23 production in children with autism spectrum disorders. J Neuroimmunol. 2009; 216(1-2):126-129. [PubMed: 19800697]

Plioplys AV, Greaves A, Kazemi K, Silverman E. Lymphocyte function in autism and Rett syndrome. Neuropsychobiology. 1994; 29(1):12-16. [PubMed: 8127418]

Poulton T, Gallagher A, Potts R, Beck C, JS. Changes in activation markers and cell membrane receptors on human peripheral blood $\mathrm{T}$ lymphocytes during cell cycle progression after PHA stimulation. Immunology. 1988; 64(3):419-25. [PubMed: 3261709]

Reddy PH, Manczak M, Zhao W, Nakamura K, Bebbington C, Yarranton G, Mao P. Granulocytemacrophage colony-stimulating factor antibody suppresses microglial activity: implications for anti-inflammatory effects in Alzheimer's disease and multiple sclerosis. J Neurochem. 2009; 111(6):1514-28. [PubMed: 19840215]

Rosen NJ, Yoshida CK, Croen LA. Infection in the first 2 years of life and autism spectrum disorders. Pediatrics. 2007; 119 (1):61-9.

Sakaguchi S, Miyara M, Costantino CM, Hafler DA. FOXP3+ regulatory T cells in the human immune system. Nat Rev Immunol. 2010; 10(7):490-500. [PubMed: 20559327]

Schäbitz WR, Krüger C, Pitzer C, Weber D, Laage R, Gassler N, Aronowski J, Mier W, Kirsch F, Dittgen T, Bach A, Sommer C, Schneider A. A neuroprotective function for the hematopoietic protein granulocyte-macrophage colony stimulating factor (GM-CSF). J Cereb Blood Flow Metab. 2008; 28(1):29-43. [PubMed: 17457367]

Serajee FJ, Zhong H, Mahbubul Huq AH. Association of Reelin gene polymorphisms with autism. Genomics 2006. 2006; 87:75-83.

Shevach EM. From vanilla to 28 flavors: multiple varieties of T regulatory cells. Immunity. 2006; 25(2):195-201. [PubMed: 16920638]

Shi L, Fatemi SH, Sidwell RW, Patterson PH. Maternal influenza infection causes marked behavioral and pharmacological changes in the offspring. J Neurosci. 2003; 23(1):297-302. [PubMed: 12514227]

Silva SC, Correia C, Fesel C, Barreto M, Coutinho AM, Marques C, Miguel TS, Ataide A, Bento C, Borges L, Oliveira G, Vicente AM. Autoantibody repertoires to brain tissue in autism nuclear families. J Neuroimmunol. 2004; 152(1-2):176-182. [PubMed: 15223250]

Skaar DA, Shao Y, Haines JL, et al. Analysis of the RELN gene as a genetic risk factor for autism. Mol Psychiatry 2005. 2005; 10:563-571.

Smith KA. Interleukin-2: inception, impact, and implications. Science. 1988; 240(4856):1169-76. [PubMed: 3131876]

So T, Lee SW, Croft M. Immune regulation and control of regulatory T cells by OX40 and 4-1BB. Cytokine Growth Factor Rev. 2008; 19(3-4):253-62. [PubMed: 18508403]

Sonderegger I, Iezzi G, Maier R, Schmitz N, Kurrer M, Kopf M. GM-CSF mediates autoimmunity by enhancing IL-6-dependent Th17 cell development and survival. J Exp Med. 2008; 205(10):228194. [PubMed: 18779348]

Song J, So T, Cheng M, Tang X, Croft M. Sustained survivin expression from OX40 costimulatory signals drives T cell clonal expansion. Immunity. 2005; 22 (5):621-31. [PubMed: 15894279]

Stubbs EG. Autistic children exhibit undetectable hemagglutination-inhibition antibody titers despite previous rubella vaccination. J Autism Child Schizophr. 1976; 6:269-274. [PubMed: 1036494]

Stubbs EG, Crawford ML. Depressed lymphocyte responsiveness in autistic children. J Autism Child Schizophr. 1977; 7(1):49-55. [PubMed: 139400]

Sweeten TL, Posey DJ, Shankar S, McDougle CJ. High nitric oxide production in autistic disorder: A possible role for interferon- $\gamma$. Biol Psychiatry. 2004; 55(4):434-437. [PubMed: 14960298] 
Todd RD, Hickok JM, Anderson GM, Cohen DJ. Antibrain antibodies in infantile autism. Biol Psychiatry. 1988; 23(6):644-647. [PubMed: 3355880]

Torres AR, Sweeten TL, Cutler A, Bedke BJ, Fillmore M, Stubbs EG, Odell D. The association and linkage of the HLA-A2 class I allele with autism. Hum Immunol. 2006; 67 (4-5):346-51. [PubMed: 16720216]

Tsuchiya KJ, Hashimoto K, Iwata Y, Tsujii M, Sekine Y, Sugihara G, Matsuzaki H, Suda S, Kawai M, Nakamura K, Minabe Y, Yagi A, Iyo M, Takei N, Mori N. Decreased serum levels of plateletendothelial adhesion molecule (PECAM-1) in subjects with high-functioning autism: a negative correlation with head circumference at birth. Biol Psychiatry. 2007; 62:1056-1058. [PubMed: 17509538]

Vargas DL, Nascimbene C, Krishnan C, Zimmerman AW, Pardo CA. Neuroglial activation and neuroinflammation in the brain of patients with autism. Ann Neurol. 2005; 57(1):67-81. [PubMed: 15546155]

Warren RP, Singh VK, Cole P, Odell JD, Pingree CB, Warren WL, DeWitt CW, McCullough M. Possible association of the extended MHC haplotype B44-SC30-DR4 with autism. Immunogenetics. 1992; 36 (4):203-7. [PubMed: 1639438]

Warren RP, Yonk J, Burger RW, Odell D, Warren WL. DR-positive T cells in autism: association with decreased plasma levels of the complement C4B protein. Neuropsychobiology. 1995; 31 (2):53-7. [PubMed: 7760985]

Wills S, Cabanlit M, Bennett J, Ashwood P, Amaral DG, Van de Water J. Detection of autoantibodies to neural cells of the cerebellum in the plasma of subjects with autism spectrum disorders. Brain Behav Immun (2009). 2009; 23(1):64-74.

Yonk LJ, Warren RP, Burger RA, Cole P, Odell JD, Warren WL, White E, Singh VK. CD4+ helper T cell depression in autism. Immunol Lett. 1990; 25(4):341-5. [PubMed: 1979061]

Ziv Y, Ron N, Butovsky O, Landa G, Sudai E, Greenberg N, Cohen H, Kipnis J, Schwartz M. Immune cells contribute to the maintenance of neurogenesis and spatial learning abilities in adulthood. Nat Neurosci. 2006; 9:268-275. [PubMed: 16415867]

Ziv Y, Schwartz M. Immune-based regulation of adult neurogenesis: implications for learning and memory. Brain Behav Immun. 2008; 22:167-176. [PubMed: 17905567] 


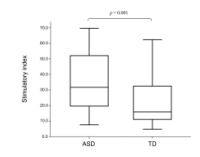

Figure 1.

Comparison of cellular responses following PHA stimulation in children with autism spectrum disorders (ASD; $\mathrm{n}=37$ ) and age-matched typically developing age-matched controls (TD; $\mathrm{n}=35$ ). Data are expressed as a stimulation index (S.I.). Horizontal box lines are $25 \%, 50 \%$ (median) and $75 \%$ of the distribution with whiskers marking 1.5 times the interquartile range. 


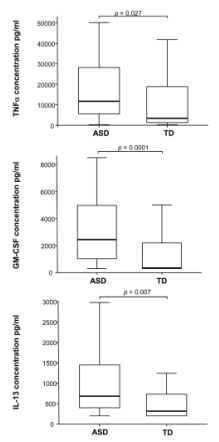

Figure 2.

Increased cytokine responses after stimulation with PHA in children with autism spectrum disorders (ASD; $\mathrm{n}=37$ ) compared with age-matched typically developing age-matched controls (TD; $\mathrm{n}=35)$. $\mathrm{y}$-axis represents cytokine levels $(\mathrm{pg} / \mathrm{ml})$ ). Horizontal box lines are $25 \%, 50 \%$ (median) and $75 \%$ of the distribution with whiskers marking 1.5 times the interquartile range. 


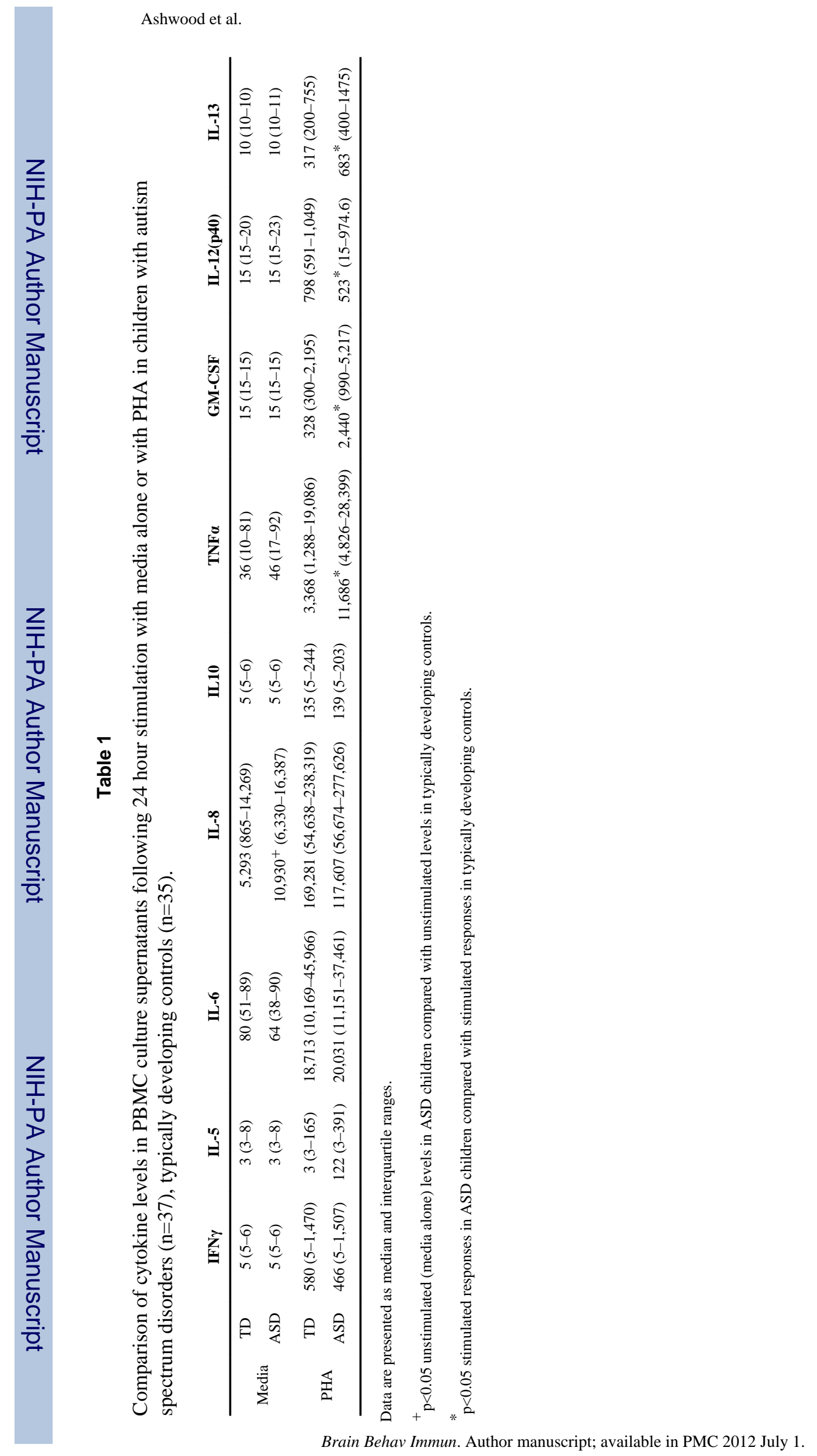

Page 19 


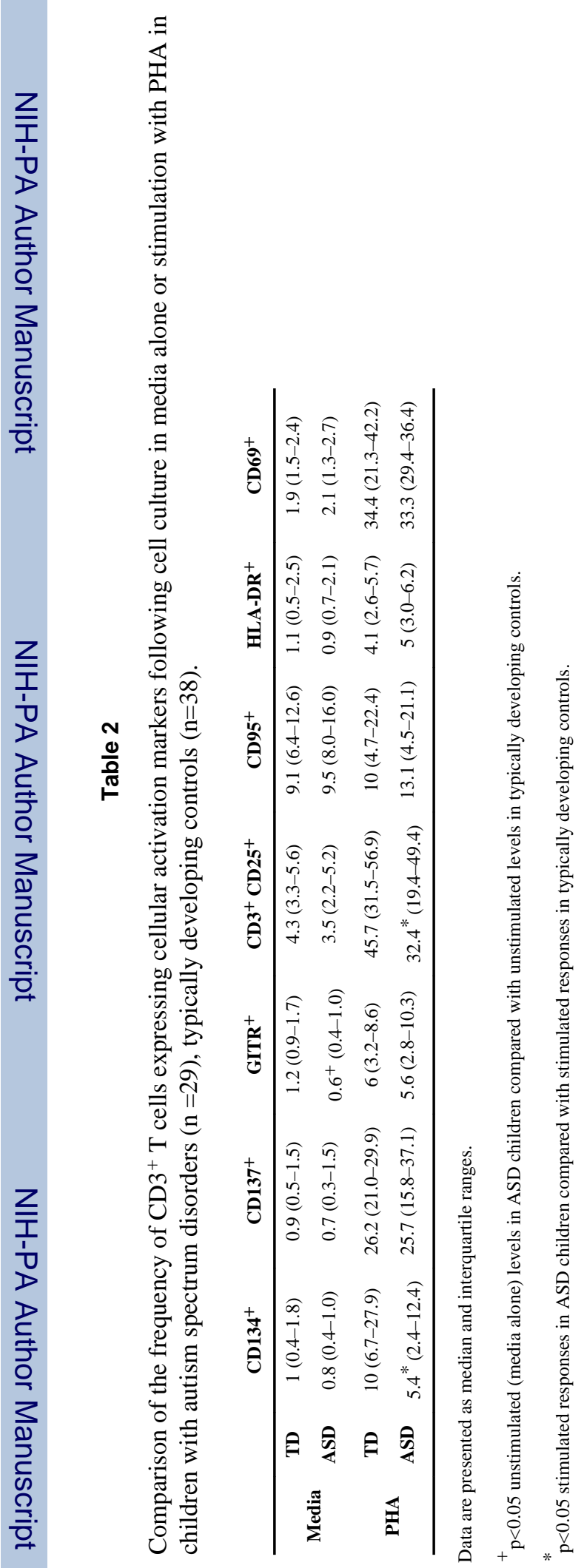




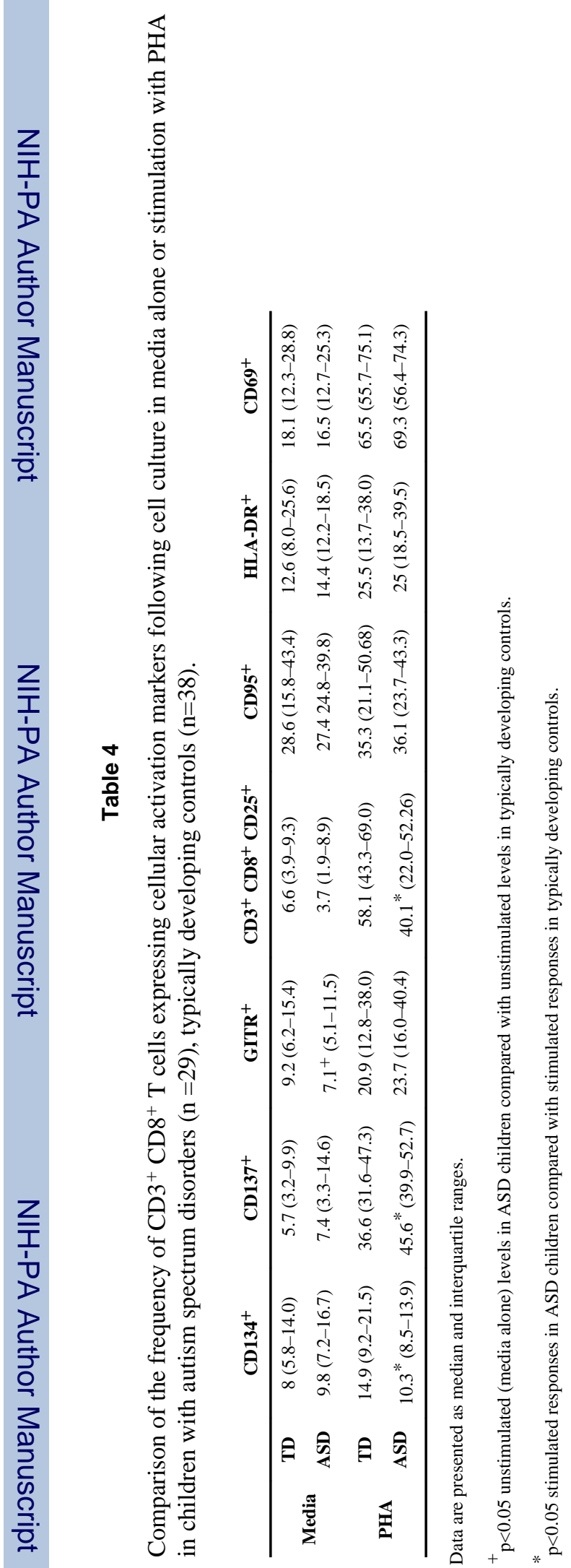

